technology, and to the unusual, if not unique, circumstance that this large collection of essays was being presented to one who, at the age of seventyseven, was still actively pursuing a life of vigorous scholarship and was at the very moment busily engaged on the preparation of a five-volume history of technology. Prof. Singer, in replying, and thanking the authors, referred, among other matters, to the valuable collaboration that he had so continuously received from his wife, Mrs. Dorothea Waley Singer, who, with other members of his family, was present at the ceremony. Others present, besides the editor of the work, included some of the contributors, Prof. V. Gordon Childe, Prof. K. J. Franklin and Dr. Douglas McKie (also representing University College, London, where Dr. Singer formerly held the University chair of the history of medicine), and also some of Dr. Singer's friends-Dr. F. A. Freeth, Mr. R. Affleck Greeves and Dr. C. T. Andrews.

Integrity of the U.S. National Bureau of Standards

THE successive publication of the report of the committee appointed in the United States on October 16 to evaluate the functions and operations of the U.S. National Bureau of Standards and of the corresponding committee, chosen by the National Academy of Sciences on November 13 to appraise the work of the Bureau in relation to battery additives, appears to have removed the dangerous challenge to the relations between science and government which had developed in the United States. The latter report completely vindicates the Bureau in its findings regarding the worthlessness of the battery additive known as $A D-X 2$ : the quality of the Bureau's work in this field is reported as excellent and better than at any time in the past. The report of the former committee was also highly favourable to the Bureau and resulted in Dr. D. V. Astin being persuaded to remain permanently at the head of the Bureau. It fully indicates the competence, integrity and loyalty of the professional staff of the Bureau, but makes some ten major recommendations for improving and strengthening the Bureau. These include more space and modern facilities for fundamental work, an additional associate director for research and the appointment of advisory groups from the membership of eight scientific and technical societies. While men of science in Great Britain will be glad to note the way in which professional opinion in the United States has removed a dangerous challenge to the integrity of scientific work, they will appreciate also the immense waste of time that has been involved and the grave risk that was at one time incurred not only of the loss of the services of a distinguished scientific worker but also of the effectiveness of a scientific agency. The episode has its meaning and warning for scientists in Britain also, where there is still insufficient understanding of the nature of scientific work among politicians and Civil servants. The conditions here are unlikely to parallel exactly those in the United States, but the force of Mr. Robert Birley's observation to the British Association at Liverpool last September is well illustrated.

\section{Quaternary Ecological Studies in Ireland}

TrFe Queen's University, Belfast, has accepted an offer by the Nuffield Foundation of a sum of $£ 12,000$, spread over four years, to establish research in quaternary ecological studies, and it is hoped to establish a scheme of study at the beginning of next session of the University. The rapid disappearance of many areas of bogland in Ulster, especially in view of the proposed utilization of peat for industrial purposes, is a matter of concern to scientists. No complete scientific description of an Irish bog has ever been made, though the work of Dr. K. Jessen, of Copenhagen, and Dr. G. F. Mitchell, of Trinity College, Dublin, has shown the possibilities. The selection for preservation of small areas of virgin bog as Nature reserves for scientific study is only a small part of the work. Studies of the vegetational succession yield important evidence of the history of the Irish flora, through the identification of pollen grains preserved in the peat, and this provides an essential chronological framework for the archæologist and the student of early Irish culture. Human relics and the effects of human interference with the environment can also be investigated in the bog flora, as well as evidence for the development of agriculture and animal husbandry and for the decline of forests. It is important that in some areas land under the bogs was once cultivated and produced cereal crops, and the study of the processes of bog formation will provide a clue to the best methods of reclamation and rehabilitation. The utilization of the actual bog or fen soils is also a matter of economic importance. The research work will be done in close co-operation with the Survey of Ulster Boglands, now being conducted under the Northern Ireland Ministry of Commerce, and will be under the general supervision of the new professor of botany in the University, Prof. J. Heslop Harrison (who has succeeded Prof. James Small, an original sponsor of the studies), supported by the professors of geography and geology, the lecturer in archæology, and other specialists.

\section{Atomic Scientists' Association}

Tre journal of the Atomic Scientists' Association, previously known as the Atomic Scientists' News, has been renamed Atomic Scientists' Journal, and commeneing with the September number (3, No. 1; 1953) appears under the new title and also with a new cover design. In the editorial for this number the purpose and aims of the Association are reaffirmed and suggestions are offered as to how the influence of the Association, frankly admitted not to be strong, may be increased and spread more widely. The main task of the Association is to supply accurate and reliable information on the scientific aspects of atomic energy and to promote informed discussion on the subject so that the new knowledge may be wisely used; it is therefore disappointing that so few atomic scientists take advantage of the medium afforded by the Association and its journal.

At the annual general meeting of the Association, held at the Clarendon Laboratory, Oxford, on June 4, the following officers were elected: President, Prof. H. S. W. Massey ; Executive Vice-President, Prof. J. Rotblat; General Secretary, Mr. G. N. Walton; Treasurer, Dr. J. H. Tait ; and Editor and Assistant Editor of the Journal, Drs. P. E. Hodgson and H. R. Allan, respectively. A brief report of the meeting is included in the September number of the Journal, with two articles. 'The first, entitled "Fundamental Particles", by Dr. Hodgson, relates to the international conference on cosmic radiation held during July at Bagnères de Bigorre (see Nature, September 12 , p. 477). The second article, "Life at Chalk River", by Freda Kinsey, is of more general interest and describes the position and community life surrounding the Chalk River plant of the Atomic Energy of 